\title{
Maternal health services utilization and its contributing factors among adolescent mothers
}

\author{
Dewi Nuryana ${ }^{1}$, Pramon Viwattanakulvanid ${ }^{2}$, Nohan Arum Romadlona ${ }^{1}$ \\ ${ }^{1}$ Knowledge Hub for Reproductive Health Indonesia, Faculty of Public Health, University of Indonesia, Depok, Indonesia \\ ${ }^{2}$ College of Public Health Sciences, Chulalongkorn University, Bangkok, Thailand
}

\begin{tabular}{l} 
Article Info \\
\hline Article history: \\
Received Jun 1, 2021 \\
Revised Nov 4, 2021 \\
Accepted Dec 2, 2021 \\
\hline
\end{tabular}

Keywords:

Delivery services utilization

Education

Knowledge

Maternal health services

Region

Residence

\begin{abstract}
Adolescent girls (15-19 years old) experienced childbirth face the higher risk for maternal mortality than older women. This study aimed to assess the utilization level of maternal health services and to identify factors that contribute to the maternal health services utilization in Indonesian adolescent mothers. The study used secondary data from 2017 Indonesia Demographic and Health Survey (IDHS) and included women who had last birth at the age of 15-19 years old which total is 866 women. Among adolescent mothers, the highest level of utilization is post-natal care (PNC) $(71.5 \%)$ followed by antenatal care (ANC) $(67.2 \%)$ then delivery services $(64.5 \%)$. Factors that associated with ANC utilization are husband/partner's education, mother's autonomy, region, husband accompanied during ANC, topic discussed during ANC, and intendedness of last birth $(\mathrm{p}<0.05)$. Factors contributed to delivery services are mother's education, mother's working status, mother's autonomy, residence, region, wealth index, health insurance, husband accompanied during ANC, and topic discussed during ANC $(\mathrm{p}<0.05)$. Whereas, for PNC utilization are knowledge of danger sign during childbirth, residence, region, and delivery services utilization $(\mathrm{p}<0.05)$. Therefore, health strategic programs which focused on adolescent mothers are necessary to improve the maternal health in Indonesia.
\end{abstract}

This is an open access article under the CC BY-SA license.

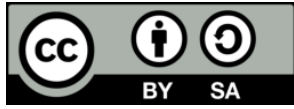

\section{Corresponding Author:}

Dewi Nuryana

Knowledge Hub for Reproductive Health Indonesia, Faculty of Public Health, University of Indonesia

Pegangsaan Timur St. No. 16, Menteng, Central Jakarta, DKI Jakarta, Indonesia

Email: dewinuryana94@gmail.com

\section{INTRODUCTION}

Maternal mortality ratio (MMR) in global is still one of major public health issues. There were approximately 295,000 women died from pregnancy and childbirth in 2017. Most of the death (94\%) happened in low and lower middle-income countries. In Indonesia, maternal mortality rate (MMR) in 2015 is 305 per 100,000 live births [1]. It failed to fulfil Millennium Development Goals (MDGs) which targets to decline MMR to 102 deaths per 100,000 livebirths in 2015 and still far to achieve Sustainable Development Goals (SDGs) to only 70 maternal deaths per 100,000 live births by 2030 .

Approximately 12 million of girls in adolescent age (15-19 years old) experience of childbirth every year in developing countries. In global, complications during pregnancies and birth delivery are the crucial factors of death for adolescent girls. The estimation of abortion that happened every year among adolescent girls is 5.6 million. As of 3.9 out of 5.6 million, the abortion was unsafe which caused health problems, morbidity, and maternal mortality. The risks of systemic infections, puerperal endometritis, and eclampsia are higher in adolescent mothers than older women. The adolescent mothers' babies also have higher risks of preterm delivery, low birth weight, and poor neonatal health [2]. In Indonesia, approximately 36 of 1,000 
adolescent girls (15-19 years old) experienced childbirth which makes this country is the second highest rate of childbirth from adolescent girls in ASEAN [3].

The maternal health services utilization has an important role in reducing MMR. Especially in developing countries, the common use intervention to reduce MMR is antenatal care (ANC). However, the use of maternal health services is still lower than the global target. Only about $50 \%$ pregnancy in developing regions received ANC services and $71 \%$ of delivery is performed by health workers in 2014 [4]. In Indonesia, the use of ANC services shows slightly better achievement than global which is $86 \%$ and for the delivery by health worker is $87 \%$ in 2014 [5]. However, the childbirth delivery rate in health facility was still low, only about $63 \%$ in 2012 [6]. This could be caused by the disparity of accessing services of maternal health between urban and rural areas and poor and rich people are still a challenge [7].

A study from several developing countries examined some factors associated to maternal health services utilization including age, education level, race, wealth, type of resident, size of household, parity, maternal health knowledge, women autonomy status, and insurance [8]. A study in Indonesia showed that some factors, such as poor maternal knowledge, low income, residents in rural area, and have a closely spaced and high births orders had associations with lower utilization of ANC [7]. However, there is still lack of studies that focused on the use of three periods of maternity health services - before, during, and after delivery especially in adolescent mothers in Indonesia.

As the decline of maternal mortality rate is still important in the Sustainable Development Goals (SDGs) 2030, this is necessary to understand the factors associated with the three period of maternal health services utilization and its contributing factors using the latest national publication data. Therefore, the aim of this study is to assess the utilization level of maternal health services and to identify factors that associate with the maternal health services utilization in Indonesian adolescent mothers. The results of this study are expected to contribute to support strategic policies and programs' approach which focused on the maternal health services utilization in adolescent mothers.

\section{RESEARCH METHOD}

The design of this study was cross-sectional survey using secondary data from 2017 Indonesia Demographic and Health Survey (IDHS). This is the latest national publication data per five years by Demographic and Health Survey program that could be representative in the whole country, as the 2022 data is not available yet. In this study, only Woman's Questionnaire was used. The total of women interviewed in the survey was 49,627 women. The inclusion criteria of this study were women who had last birth at the age of 15-19 years old. There were no exclusion criteria in this study.

The study used Individual Women's data - Individual Record (IR) dataset from IDHS data. Data cleaning was processed using Stata 16. All data was weighted using function V005/1,000,000 when input to calculation. The total number of women that included in the dataset is 49,627 women. From these women, this study only selected women who had given birth within last five years before survey which is 15,021 observations and those who had last birth at the age of 15-19 years old within five years before the survey which is 866 observations. The flow of data cleaning process is displayed in Figure 1.

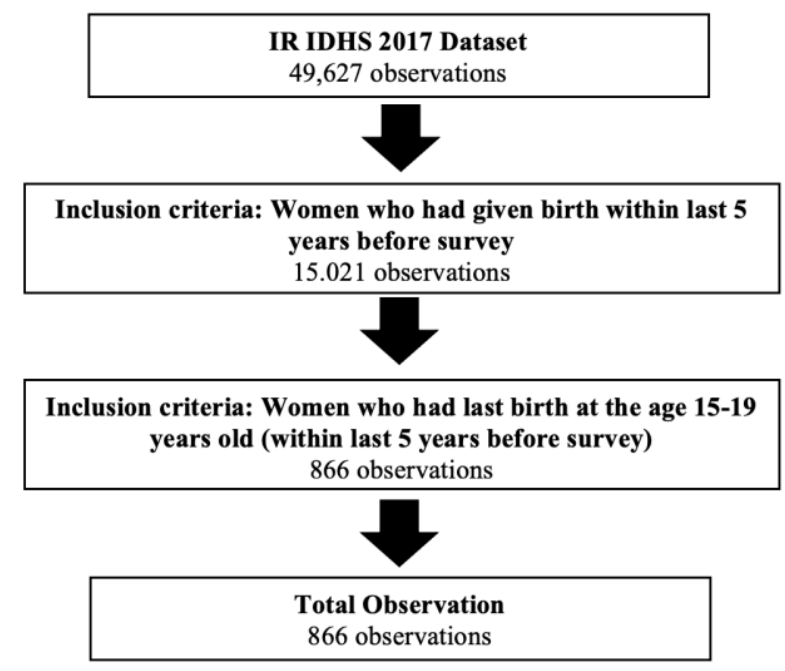

Figure 1. Data cleaning process 


\subsection{Dependent variables}

The dependent variable of this study is maternal health services utilization which consists of ANC, delivery services, and post-natal care (PNC). For the Antenatal care, the variable will be composited from three variables such as frequency of ANC visit, timing of the first ANC, and ANC provider. Delivery services variable will be composited from two variables which are delivery assistant and place of delivery. Postnatal care variable will be composited from three variables such as PNC check, first timing of PNC, and person who conducted PNC. The calculations of the scores are as follows: i) Antenatal care utilization: Classified from the total variables calculation of frequency of ANC visit, first timing of ANC visit, and ANC provider. 0: Poor utilization if the total score is 0-2 and 1: Good utilization if the total score is 3; ii) Delivery services utilization: Classified from the total variables calculation of delivery assistant and place of delivery. 0: Poor utilization if the total score is $0-1$ and 1: Good utilization if the total score is 2; iii) Postnatal care utilization: Classified from the total variables calculation of PNC check, first timing of PNC, and person who conducted PNC (0: Poor utilization if the total score is 0-2 and 1: Good utilization if the total score is 3).

\subsection{Independent variables}

The independent variables of this study are education of mothers, education of husband/partner, working status of mothers, working of husband/partner, knowledge of danger sign during pregnancy, knowledge of danger sign during delivery, knowledge of danger sign during postpartum period, and mother's autonomy for seeking healthcare, type of residence, region, wealth index, insurance coverage, discussion during pregnancy, intendedness of last birth, parity, and complication during pregnancy. As to follow the continuum care concept, then ANC utilization is included as an independent variable for delivery services utilization and PNC utilization. Whereas the delivery services utilization is included as an independent variable for PNC utilization.

\subsection{Data analysis}

The data analysis of this study was performed using Stata 16 software. Descriptive analysis was used to describe the dependent variables which are ANC, delivery services, and PNC; and the independent variables which consisting of predisposing, enabling, and need factors. Since all variables are categorical, data was presented in the frequency distribution and percentages. The association of each independent variables and dependent variables are examined by bivariate analysis using simple logistic regression. The variables with the significant level at $\mathrm{p}<0.25$ was included in multivariable analysis. The multivariable analysis used multiple logistic regressions to assess the association between dependent variables and independent variables.

\section{RESULTS AND DISCUSSION}

\subsection{Sample characteristics}

Table 1 shows that nearly half of the mothers have junior high school as their highest education level, while most of the husbands or partners (36.9\%) have senior high school/university as their highest level of education. Seventy percent of mothers are not working, contrast to the husbands or partners which almost all of them are working. Regarding the mother's knowledge, $60.9 \%$ have poor knowledge of danger sign during pregnancy, $66.6 \%$ have poor knowledge of danger sign during delivery, and $84.6 \%$ have poor knowledge of danger sign during postpartum period. Most of the mothers have a full or partial autonomy of seeking healthcare for themselves $(86.3 \%)$.

Most of the mothers lived in rural area (65.4\%) and in Java-Bali region (59.0\%). More than half of the mothers in the poorest and poorer wealth quintile while gradually decrease from middle into richest quintile. Numbers of mothers who have health insurance are slightly higher than those who do not have health insurance $(51.3 \%$ and $48.7 \%$, respectively). During ANC visit, most of the mothers are accompanied by their husband (79\%). From the total of six discussion topics during ANC visit, 53.8\% mothers have discussed 0-4 topic(s) with health providers and 46.2\% discussed 5-6 topics. About ninety percent of mother's last births are intended and $97.4 \%$ only have one child. Most of the mothers are reported never have any complication $(84.8 \%$ ) compared to $15.2 \%$ of mothers ever have complication during their pregnancy.

\subsection{Utilization of maternal health services}

\subsubsection{Antenatal care}

Table 2 shows that most of mothers have ANC visit for more than four times during pregnancy. For the timing of first ANC, 73.5\% visit within the first three months of their pregnancy. About $96 \%$ mothers visit health provider for health examination during pregnancy. Based on those three indicators, adolescent mothers who have a good utilization are $67.2 \%$ compared to those who have poor utilization which are $32.8 \%$. 
Table 1. Distribution of sample characteristics of adolescent mothers in Indonesia $(n=866)$

\begin{tabular}{|c|c|c|}
\hline Variables & $\mathrm{n}$ & $\%$ \\
\hline \multicolumn{3}{|l|}{ Education of mothers } \\
\hline None/primary & 226 & 26.2 \\
\hline Junior high school & 413 & 47.7 \\
\hline Senior high school/University & 227 & 26.1 \\
\hline \multicolumn{3}{|l|}{ Education of husband/partner } \\
\hline None/primary & 292 & 33.7 \\
\hline Junior high school & 254 & 29.4 \\
\hline Senior high school/University & 320 & 36.9 \\
\hline \multicolumn{3}{|l|}{ Working status of mother } \\
\hline No & 607 & 70.0 \\
\hline Yes & 259 & 30.0 \\
\hline \multicolumn{3}{|l|}{ Working status of husband/partner } \\
\hline No & 15 & 1.4 \\
\hline Yes & 851 & 98.6 \\
\hline \multicolumn{3}{|l|}{$\begin{array}{l}\text { Knowledge of danger sign during } \\
\text { pregnancy }\end{array}$} \\
\hline Poor $(<2)$ & 526 & 60.9 \\
\hline Good $(\geq 2)$ & 340 & 39.1 \\
\hline \multicolumn{3}{|l|}{$\begin{array}{l}\text { Knowledge of danger sign during } \\
\text { childbirth }\end{array}$} \\
\hline Poor $(<2)$ & 577 & 66.6 \\
\hline Good $(\geq 2)$ & 289 & 33.4 \\
\hline \multicolumn{3}{|l|}{$\begin{array}{l}\text { Knowledge of danger sign during } \\
\text { postpartum period }\end{array}$} \\
\hline Poor $(<1)$ & 732 & 84.6 \\
\hline Good $(\geq 1)$ & 134 & 15.4 \\
\hline $\begin{array}{l}\text { Mother's autonomy for seeking } \\
\text { healthcare }\end{array}$ & & \\
\hline Not at all & 119 & 13.7 \\
\hline Full or partial & 747 & 86.3 \\
\hline \multicolumn{3}{|l|}{ Type of residence } \\
\hline Rural & 566 & 65.4 \\
\hline Urban & 300 & 34.6 \\
\hline \multicolumn{3}{|l|}{ Region } \\
\hline Java-Bali & 511 & 59.0 \\
\hline Sumatera & 159 & 18.3 \\
\hline Kalimantan & 70 & 8.1 \\
\hline Sulawesi & 71 & 8.2 \\
\hline Maluku-Papua & 55 & 6.4 \\
\hline \multicolumn{3}{|l|}{ Wealth index } \\
\hline Poorest & 262 & 30.3 \\
\hline Poorer & 249 & 28.8 \\
\hline Middle & 202 & 23.3 \\
\hline Richer & 109 & 12.5 \\
\hline Richest & 44 & 5.1 \\
\hline \multicolumn{3}{|l|}{ Health insurance } \\
\hline Doesn't have & 422 & 48.7 \\
\hline Have & 444 & 51.3 \\
\hline \multicolumn{3}{|l|}{ Husband accompanied during ANC } \\
\hline No & 182 & 21.0 \\
\hline Yes & 684 & 79.0 \\
\hline \multicolumn{3}{|l|}{ Topic discussed during ANC } \\
\hline $0-4$ topic(s) & 467 & 53.8 \\
\hline 5-6 topics & 399 & 46.2 \\
\hline \multicolumn{3}{|l|}{ Intendedness of last birth } \\
\hline Not wanted & 81 & 9.3 \\
\hline Wanted & 785 & 90.7 \\
\hline \multicolumn{3}{|l|}{ Parity } \\
\hline$>1$ child & 22 & 2.6 \\
\hline 1 child & 844 & 97.4 \\
\hline \multicolumn{3}{|l|}{ Had complication during pregnancy } \\
\hline No & 734 & 84.8 \\
\hline Yes & 132 & 15.2 \\
\hline
\end{tabular}

The association of contributing factors and antenatal care utilization were first analysed using binary logistic regression before proceed to multivariable analysis. Independent variables that have the p-value less than 0.25 will be continue to test in multivariable analysis. In ANC utilization, variables that are passed to multivariable analysis are education of husband/partner, working status of husband/partner, knowledge of

Int J Public Health Sci, Vol. 11, No. 1, March 2022: 77-87 
danger sign during pregnancy, knowledge of danger sign during childbirth, knowledge of danger sign during postpartum period, women's autonomy for seeking healthcare, region, wealth index, husband accompanies during ANC, topic discussed during pregnancy, intendedness of last birth, and parity.

Table 2. Distribution of antenatal care $(n=866)$

\begin{tabular}{lcc}
\multicolumn{1}{c}{ Variables } & $\mathrm{n}$ & $\%$ \\
\hline Frequency of ANC Visit & & \\
<4 visit(s) & 83 & 9.6 \\
Z4 visits & 783 & 90.4 \\
Timing of first ANC visit & & \\
> 3 months & 229 & 26.5 \\
<3 month(s) & 637 & 73.5 \\
ANC provider & & \\
Non-health providers & 37 & 4.3 \\
Health providers & 829 & 95.7 \\
ANC utilization & & \\
Poor (0-2) & 284 & 32.8 \\
Good (3) & 582 & 67.2 \\
\hline
\end{tabular}

Table 3 shows that an adolescent mother who has high education of husband has $45 \%$ lower chance to get a good utilization of ANC than those who has low education husband. This finding is contrast to another studies that found the positive correlation of husband/partner's education with ANC utilization [9]. Husband/partner with high education should be more aware of the health needs of their wives, however they may be busier with work or were in college when their adolescent wives got pregnant resulting no time to accompany during ANC visit which is one of the influential factors to ANC utilization. Even though, in this study working husband/partners are not significantly related to utilization of ANC but other findings showed that mothers whom their husbands are working and cannot accompany them for prenatal check are less likely to use ANC services [10], [11].

Table 3. Factors associated to utilization of antenatal care among adolescent mothers in Indonesia $(n=866)$

\begin{tabular}{|c|c|c|c|c|}
\hline Variables & Unadjusted OR & $95 \% \mathrm{CI}$ & Adjusted OR & $95 \% \mathrm{CI}$ \\
\hline \multicolumn{5}{|c|}{ Education of husband/partner (Ref: None/primary) } \\
\hline Junior high school & 0.89 & $0.62-1.29$ & 0.79 & $0.53-1.18$ \\
\hline \multicolumn{5}{|l|}{ school/University } \\
\hline \multicolumn{5}{|c|}{ Working status of husband/partner (Ref: No) } \\
\hline Yes & 2.19 & $0.69-6.97$ & 1.00 & $0.27-3.72$ \\
\hline \multicolumn{5}{|c|}{ Knowledge of danger sign during pregnancy (Ref: Poor) } \\
\hline Good & $1.94 *$ & $1.43-2.63$ & 1.45 & $1.00-2.12$ \\
\hline \multicolumn{5}{|c|}{ Knowledge of danger sign during childbirth (Ref: Poor) } \\
\hline Good & $1.91 *$ & $1.39-2.63$ & 1.15 & $0.76-1.71$ \\
\hline \multicolumn{5}{|c|}{ Knowledge of danger sign during postpartum period (Ref: Poor) } \\
\hline Good & $1.57 *$ & $1.03-2.39$ & 1.11 & $0.68-1.82$ \\
\hline \multicolumn{5}{|c|}{ Mother's autonomy for seeking healthcare (Ref: Not at all) } \\
\hline Full or partial & 1.40 & $0.94-2.09$ & $1.61 *$ & $1.03-2.50$ \\
\hline \multicolumn{5}{|l|}{ Region (Ref: Java) } \\
\hline Sumatera & $0.62 *$ & $0.43-0.91$ & 0.68 & $0.45-1.03$ \\
\hline Kalimantan & $0.47 *$ & $0.28-0.79$ & $0.54 *$ & $0.31-0.95$ \\
\hline Sulawesi & $0.44 *$ & $0.26-0.73$ & 0.71 & $0.40-1.23$ \\
\hline Eastern Indonesia & $0.45^{*}$ & $0.26-0.80$ & 0.96 & $0.49-1.86$ \\
\hline \multicolumn{5}{|c|}{ Wealth index (Ref: Poorest) } \\
\hline Poorer & $1.55^{*}$ & $1.07-2.24$ & 1.21 & $0.79-1.86$ \\
\hline Middle & 1.26 & $0.86-1.85$ & 1.05 & $0.67-1.64$ \\
\hline Richer & $1.86^{*}$ & $1.13-3.05$ & 1.57 & $0.87-2.82$ \\
\hline Richest & 1.84 & $0.90-3.77$ & 1.75 & $0.77-4.00$ \\
\hline \multicolumn{5}{|c|}{ Husband accompanied during ANC (Ref: No) } \\
\hline Yes & $3.00 *$ & $2.15-4.21$ & $2.42 *$ & $1.66-3.52$ \\
\hline \multicolumn{5}{|c|}{ Topic discussed during ANC (Ref: 0-4 topic(s)) } \\
\hline $5-6$ topics & $2.73^{*}$ & $2.02-3.69$ & $2.24 *$ & $1.61-3.11$ \\
\hline \multicolumn{5}{|c|}{ Intendedness of last birth (Ref: Not wanted) } \\
\hline Wanted & $3.29 *$ & $2.06-5.26$ & $3.09 *$ & $1.82-5.24$ \\
\hline \multicolumn{5}{|c|}{ Parity (Ref: $>1$ child) } \\
\hline 1 child & 1.90 & $0.82-4.43$ & 1.30 & $0.51-3.27$ \\
\hline
\end{tabular}


Adolescent mothers who had a good knowledge of danger sign during pregnancy, childbirth, and postpartum period are also has positive correlation with good ANC utilization, although the results are not significant. The findings are similar with other studies that reported low proportion of mothers with knowledge and awareness of danger signs during pregnancy contribute to poor utilization of ANC services [12], [13]. Adolescent mothers with good knowledge of danger signs during pregnancy will be more willing to check their pregnancy due to awareness of safe pregnancy.

Other than knowledge, mother's autonomy to seek healthcare for them is also a significant factor. In some places, adolescent mothers who lived in traditional family may have less authority to make decision on their own about ANC visit and delivery services [14]. Adolescent mothers who are able to make decision about their own health will encourage gaining maternal knowledge when they get pregnant and will not hesitate to decide for seeking ANC services. It is relevant with the result that shows mother who has full or partial autonomy for seeking healthcare has 1.61 times more likely to have a good utilization of ANC.

Adolescent mothers who lived outside Java-Bali region have lower chance to get a good utilization of ANC. This reflects the disparity of healthcare between regional in Indonesia. Average of distances from home to hospital are widely vary from only 0.5 kilometre in Jakarta to 29.0 kilometres in Central Sulawesi [15]. In term of economic and infrastructure, Java-Bali region, Indonesia is more developed than other regions. In addition, number of health facilities and health providers are disproportionately clustered in Java particularly in urban area and are often inaccessible to the poor [16]. These barriers may give a difficulty for many adolescent mothers outside Java-Bali to access ANC services during pregnancy.

Good utilization of ANC is also more likely in adolescent mothers who had been accompanied by their husband/partner during ANC visit (AOR=2.42, 95\% CI 1.66-3.52). Adolescent mothers tend to be reluctant to access maternal health services especially during pregnancy due to negative stigma of adolescent pregnancy in the community. Support from husband/partner in accompany them during pregnancy health check will encourage mothers to be routinely visit for ANC. Another study also found that mothers who had been accompany by their husband/partner has positive association with receiving antenatal care from a health trained provider $(\mathrm{AOR}=4.5,95 \% \mathrm{CI} 2.3-8.7)$. This study indicated that male involvement is one of key factors with adolescent mother's utilization of skilled maternal health services during pregnancy [10].

Both men and women need to be involved in maternal health education during pregnancy. Another study reported the preferred topics during ANC visit which were preparation for birth and plan of complication readiness, pregnancy description, how to care pregnancy women, complication during pregnancy and after childbirth, men's role during pregnancy, and baby care after childbirth. Relevant with this study's result that found adolescent mothers that discussed more topics with health providers during pregnancy is 2.24 times more likely to have a good utilization of ANC. It indicates comprehensiveness of discussion between mothers and health providers make mothers be more knowledgeable about maternal health and routinely visit for antenatal care [17].

\subsubsection{Delivery services}

Table 4 shows the distribution of delivery services among adolescent mothers in Indonesia. The result shows that most of them $(70.7 \%)$ are assisted by health providers during childbirth and gave childbirth in health facility $(75.6 \%)$. Based on those two indicators, the utilization level of delivery services are classified into poor utilization and good utilization. Adolescent mothers who have a good utilization in delivery services are $64.5 \%$ and those who have a poor utilization in delivery services are $35.5 \%$.

\begin{tabular}{lcc}
\multicolumn{1}{c}{ Table 4. Distribution of delivery services $(\mathrm{n}=866)$} \\
\hline \multicolumn{1}{c}{ Variables } & $\mathrm{n}$ & $\%$ \\
\hline Delivery assistant & & \\
Non-health providers & 254 & 29.3 \\
Health providers & 612 & 70.7 \\
Place of delivery & & \\
Non health facility & 212 & 24.4 \\
Health facility & 654 & 75.6 \\
Delivery utilization & & \\
Poor (0-1) & 307 & 35.5 \\
Good (2) & 559 & 64.5 \\
\hline
\end{tabular}

In delivery services utilization, variables that proceeded to multivariable are education of mother, working status of mother, knowledge of danger sign during pregnancy, knowledge of danger sign during childbirth, knowledge of danger sign during postpartum period, mother's autonomy for seeking healthcare, type of residence, region, wealth index, health insurance, husband accompanied during ANC, topic discussed during pregnancy, parity, and ANC utilization. 
Table 5 shows that the higher education of adolescent mothers increased the odds to have good delivery services utilization. Adolescent mothers who have senior high school or university as their highest level of education is 1.68 times more likely to get a good utilization of delivery services. This in line with the results of other studies that reported women's education is the main contributing factor of the utilization of ANC, delivery at health facility by qualified health providers and postnatal care services. Mothers with higher education have higher chance to have knowledge of the advantages of the utilization of qualified maternal health services and the required empowerment to access care [18], [19]. They may also be more aware of maternity risks and seek to safe delivery services.

Adolescent mothers who full or partial autonomy is 1.68 times more likely to have a good delivery services utilization compared to those who have no autonomy at all. Those with the authority can decide better about seeking health care including delivery services. Since pregnancy, they could plan about the place of delivery and whom they want to be assisted in childbirth. If mothers have no authority then family members will decide about their health and in some rural areas often expect them to give birth with traditional birth attendance at home [20], [21].

Adolescent mothers who lived in urban area have higher chance to have a good utilization of delivery services. This is likely due to proximity of distance, number of health facility, and number of health providers which are more well distributed in urban than in rural areas. When the signs of childbirth come, urban mothers tend to get treatment faster because they have closer access and more options to health services. Meanwhile, adolescent mothers in rural areas if they are not well prepared for delivery and are far from the health facilities they may tend to deliver at home. Furthermore, adolescent mothers may be less exposed with maternal services and more familiar with traditional birth attendants especially in rural areas [21]. Another also have reported that most women in rural areas, rate the traditional birth attendants (TBAs) services as being of higher quality than health providers, particularly in term of interpersonal relationships and communications [22].

Similar with ANC utilization, adolescent mothers who lived outside Java-Bali region are less likely to have a good utilization of delivery services. Regions that significantly lower are Sumatera (AOR=0.44, 95\% CI 0.29-0.66) and Kalimantan (AOR=0.23, 95\% CI 0.13-0.40). In Java region, the large number of midwives has been found to be a crucial factor of delivery assisted by qualified health providers [23]. The proximity of access and a lot of referral health facilities can provide more easiness to seek delivery services for adolescent mothers who lived in Java-Bali, especially if they deliver with complications.

Utilization of delivery services is also influenced by the wealth index or economic status of adolescent mothers. Mothers who have higher quintile of wealth index are more likely to have a good delivery services. It is easier for rich women to get access to health facilities and health workers because they can cover the costs of transportation, delivery service cost and cost of postnatal services. They may be less worried about the cost of delivery even if they experience complications. Poor adolescents are also more likely to be disengaged from social networks, thus, less likely to be reached by programs aiming to improve maternal health service utilization of adolescent mothers [24], [25].

Similarly, a study also found that economic status of the adolescent mother has positive association with maternal health services utilization with adolescents in the richer group has better utilization of maternity care than the poorer group. In terms of economic factors, adolescent mothers who have health insurance do not need to worry about accessing childbirth services. Indonesia has Jaminan Kesehatan Nasional (JKN) or National Health Insurance which also covers the cost of childbirth. Indonesia also has a special insurance for delivery services called Jampersal, but its utilization is still not optimal. However, the results show that with ownership of health insurance, adolescent mothers in Indonesia will have a higher utilization of delivery services. Health insurance programs that comprehensively cover the poor mothers may help to reduce the cost barrier in delivery services [26].

Another factor that associated with good utilization of delivery services is husband/partner's role in accompanying their wives during ANC visit. Adolescent mother who accompanied by their husband/partner during ANC is 1.48 times more likely to get a good delivery services utilization. This is in line with the study which also found that husbands accompanying their wives was positively associated with women give birth at a health facility $(\mathrm{AOR}=1.5,95 \%$ CI $0.8-3.1)$ [10].

This proves the advantages of support from partners in seeking delivery services. Adolescent mothers who are accompanied by their husbands during ANC visit are also having a good utilization of ANC which can also gain a sense of awareness to take part in using childbirth services. This is also likely for the mothers and their husband/partner to prepare and plan better for whatever is needed for delivery, such as place of delivery, transportation, and who will be assisted in delivery.

The importance of planning since pregnancy for utilization of delivery services emphasizes the association between ANC utilization and delivery services utilization. Adolescent mothers who have good ANC utilization are more likely to have a good delivery services. Although the result is not statistically significant, this shows that the concept of continuum of care regarding mothers who use ANC services will 
tend to be good at use of childbirth services. Mothers who visit for ANC will have better knowledge about safe delivery services for themselves and their babies and will be better prepared for delivery. Other studies also reported that ANC visit for more than four times associated with adolescent mothers to use delivery services [27], [28].

Table 5. Factors associated to utilization of delivery services among adolescent mothers

\begin{tabular}{|c|c|c|c|c|}
\hline Variables & Unadjusted OR & $95 \% \mathrm{CI}$ & Adjusted OR & $95 \% \mathrm{CI}$ \\
\hline \multicolumn{5}{|c|}{ Education of mother (Ref: None/primary) } \\
\hline Junior high school & 1.37 & $0.98-1.91$ & 1.21 & $0.83-1.76$ \\
\hline Senior high school /University & $1.80 *$ & $1.22-2.66$ & $1.68 *$ & $1.05-2.68$ \\
\hline \multicolumn{5}{|c|}{ Working status of mother (Ref: No) } \\
\hline Yes & $1.47 *$ & $1.08-2.01$ & $1.56^{*}$ & $1.10-2.20$ \\
\hline \multicolumn{5}{|c|}{ Knowledge of danger sign during pregnancy (Ref: Poor) } \\
\hline Good & $1.47 *$ & $1.10-1.97$ & 1.05 & $0.72-1.51$ \\
\hline \multicolumn{5}{|c|}{ Knowledge of danger sign during childbirth (Ref: Poor) } \\
\hline Good & $1.52 *$ & $1.12-2.06$ & 1.09 & $0.74-1.61$ \\
\hline \multicolumn{5}{|c|}{ Knowledge of danger sign during postpartum period (Ref: Poor) } \\
\hline Good & 1.28 & $0.86-1.91$ & 0.88 & $0.55-1.41$ \\
\hline \multicolumn{5}{|c|}{ Mother's autonomy for seeking healthcare (Ref: Not at all) } \\
\hline Full or partial & $1.55^{*}$ & $1.05-2.30$ & $1.68 *$ & $1.09-2.60$ \\
\hline \multicolumn{5}{|l|}{ Type of residence (Ref: Rural) } \\
\hline Urban & $2.20 *$ & $1.61-3.01$ & $1.72 *$ & $1.21-2.44$ \\
\hline \multicolumn{5}{|l|}{ Region (Ref: Java) } \\
\hline Sumatera & $0.42 *$ & $0.29-0.61$ & $0.44 *$ & $0.29-0.66$ \\
\hline Kalimantan & $0.23^{*}$ & $0.14-0.39$ & $0.23 *$ & $0.13-0.40$ \\
\hline Sulawesi & $0.49 *$ & $0.30-0.82$ & 0.56 & $0.31-1.00$ \\
\hline Eastern Indonesia & $0.47 *$ & $0.27-0.83$ & 0.59 & $0.30-1.13$ \\
\hline \multicolumn{5}{|l|}{ Wealth index (Ref: Poorest) } \\
\hline Poorer & $1.47^{*}$ & $1.03-2.09$ & 1.00 & $0.67-1.50$ \\
\hline Middle & $2.49 *$ & $1.68-3.70$ & $1.60 *$ & $1.02-2.52$ \\
\hline Richer & $3.11 *$ & $1.87-5.20$ & 1.68 & $0.93-3.04$ \\
\hline Richest & $2.93 *$ & $1.40-6.11$ & 1.39 & $0.60-3.21$ \\
\hline \multicolumn{5}{|c|}{ Health insurance (Ref: Doesn't have) } \\
\hline Have & $1.44 *$ & $1.09-1.90$ & $1.42 *$ & $1.04-1.93$ \\
\hline \multicolumn{5}{|c|}{ Husband accompanied during ANC (Ref: No) } \\
\hline Yes & $2.19 *$ & $1.57-3.05$ & $1.69 *$ & $1.15-2.47$ \\
\hline \multicolumn{5}{|c|}{ Topic discussed during ANC (Ref: 0-4 topic(s)) } \\
\hline 5-6 topics & $1.96^{*}$ & $1.47-2.61$ & $1.48 *$ & $1.07-2.05$ \\
\hline \multicolumn{5}{|l|}{ Parity (Ref: >1 child) } \\
\hline 1 child & 2.12 & $0.91-4.95$ & 1.66 & $0.67-4.08$ \\
\hline \multicolumn{5}{|l|}{ ANC utilization (Ref: Poor) } \\
\hline Good & $1.54 *$ & $1.15-2.07$ & 1.11 & $0.79-1.55$ \\
\hline
\end{tabular}

\subsubsection{Postnatal care}

Table 6 shows the distribution of postnatal care among adolescent mothers in Indonesia. The percentage of mothers who receive PNC check are $90.2 \%$, first PNC within six hours until three days are $83.3 \%$ compared to the percentage of those with more than three days (12.9\%) and those who received PNC by health provider are $83 \%$. Based on those three variables, utilization levels of postnatal care are grouped into poor utilization and good utilization. Adolescent who has a good utilization of postnatal care are $28.5 \%$, while those who have poor utilization of postnatal care are $71.5 \%$.

Table 6. Distribution of postnatal care $(n=866)$

\begin{tabular}{lcc}
\multicolumn{1}{c}{ Variables } & $\mathrm{n}$ & $\%$ \\
\hline Postnatal check to mothers & & \\
No & 85 & 9.8 \\
Yes & 780 & 90.2 \\
First timing of PNC & & \\
>24 hours & 145 & 16.7 \\
<=24 hours & 721 & 83.3 \\
Person who conducted PNC & & \\
Non-health provider & 148 & 17.0 \\
Health provider & 718 & 83.0 \\
PNC utlization & & \\
Poor (0-2) & 247 & 28.5 \\
Good (3) & 619 & 71.5 \\
\hline
\end{tabular}

Int J Public Health Sci, Vol. 11, No. 1, March 2022: 77-87 
Among independent variables that continued to multivariable analysis in utilization of PNC are education of mothers, education of husband/partner, working status of mothers, working status of husband/partner, knowledge of danger sign during pregnancy, knowledge of danger sign during childbirth, knowledge of danger sign during postpartum period, type of residence, region, wealth index, health insurance, husband accompanied during ANC, topic discussed during pregnancy, intendedness of last birth, parity, ANC utilization, and delivery services utilization.

In Table 7 it shows that adolescent mothers who have a good knowledge of danger sign during pregnancy, childbirth, and postpartum is more likely to have a good PNC utilization. Another study also found that low utilization postnatal care services was influenced by poor knowledge of complications during pregnancy, delivery, and postpartum period [29]. If mothers have a good knowledge of danger signs, they will be able to understand better that pregnancy, childbirth, and postpartum period are risky times, thus they will continue to use PNC services properly and seek services.

Table 7. Factors associated to utilization of postnatal care among adolescent mothers in Indonesia $(\mathrm{n}=866)$

\begin{tabular}{|c|c|c|c|c|}
\hline Variables & Unadjusted OR & $95 \% \mathrm{CI}$ & Adjusted OR & $95 \% \mathrm{CI}$ \\
\hline \multicolumn{5}{|c|}{ Education of mother (Ref: None/primary) } \\
\hline Junior HS & $1.69^{*}$ & $1.19-2.39$ & 1.57 & $0.92-2.67$ \\
\hline Senior HS/University & $1.69^{*}$ & $1.13-2.53$ & 1.35 & $0.66-2.75$ \\
\hline \multicolumn{5}{|c|}{ Education of husband/partner (Ref: None/primary) } \\
\hline Junior HS & 1.37 & $0.94-1.99$ & 1.11 & $0.64-1.93$ \\
\hline Senior HS/University & 1.21 & $0.85-1.71$ & 1.01 & $0.55-1.87$ \\
\hline \multicolumn{5}{|c|}{ Working status of mother (Ref: No) } \\
\hline Yes & $1.47 *$ & $1.05-2.06$ & 1.45 & $0.89-2.35$ \\
\hline \multicolumn{5}{|c|}{ Working status of husband/partner (Ref: No) } \\
\hline Yes & 2.04 & $0.64-6.55$ & 2.57 & $0.45-14.8$ \\
\hline \multicolumn{5}{|c|}{ Knowledge of danger sign during pregnancy (Ref: Poor) } \\
\hline Good & $2.23^{*}$ & $1.61-3.10$ & 1.43 & $0.86-2.39$ \\
\hline \multicolumn{5}{|c|}{ Knowledge of danger sign during childbirth (Ref: Poor) } \\
\hline Good & $2.39 *$ & $1.69-3.39$ & $1.92 *$ & $1.12-3.28$ \\
\hline \multicolumn{5}{|c|}{ Knowledge of danger sign during postpartum period (Ref: Poor) } \\
\hline Good & $1.78^{*}$ & $0.76-1.75$ & 1.11 & $0.56-2.19$ \\
\hline \multicolumn{5}{|c|}{ Type of residence (Ref: Rural) } \\
\hline \multirow{2}{*}{\multicolumn{5}{|c|}{ Region (Ref: Java) }} \\
\hline & & & & \\
\hline Sumatera & $0.24 *$ & $0.16-0.35$ & $0.29 *$ & $0.16-0.52$ \\
\hline Kalimantan & $0.21 *$ & $0.12-0.35$ & $0.42 *$ & $0.20-0.88$ \\
\hline Sulawesi & $0.43 *$ & $0.25-0.74$ & 0.73 & $0.33-1.58$ \\
\hline Eastern Indonesia & $0.31 *$ & $0.17-0.55$ & 0.42 & $0.17-1.07$ \\
\hline \multicolumn{5}{|c|}{ Wealth index (Ref: Poorest) } \\
\hline Poorer & $2.06^{*}$ & $1.41-3.00$ & 1.55 & $0.87-2.77$ \\
\hline Middle & $2.56^{*}$ & $1.69-3.89$ & 1.01 & $0.54-1.90$ \\
\hline Richer & $2.53 *$ & $1.50-4.25$ & 0.66 & $0.28-1.53$ \\
\hline Richest & $2.11 *$ & $1.02-4.38$ & 0.47 & $0.15-1.54$ \\
\hline \multicolumn{5}{|c|}{ Health insurance (Ref: Doesn't have) } \\
\hline Have & 2.14 & $0.92-1.66$ & 0.93 & $0.61-1.43$ \\
\hline \multicolumn{5}{|c|}{ Husband accompanied during ANC (Ref: No) } \\
\hline Yes & $2.49 *$ & $1.77-3.50$ & 1.62 & $0.95-2.76$ \\
\hline \multicolumn{5}{|c|}{ Topic discussed during ANC (Ref: $0-4$ topic(s)) } \\
\hline $5-6$ topics & $2.16^{*}$ & $1.59-2.95$ & 1.14 & $0.73-1.80$ \\
\hline \multicolumn{5}{|c|}{ Intendedness of last birth (Ref: Unwanted) } \\
\hline Wanted & 0.73 & $0.42-1.25$ & 0.52 & $0.23-1.16$ \\
\hline \multicolumn{5}{|l|}{ Parity (Ref: >1 child) } \\
\hline \multirow{2}{*}{\multicolumn{5}{|c|}{ ANC utilization (Ref: Poor) }} \\
\hline & & & & \\
\hline Good & $1.80^{*}$ & $1.33-2.45$ & 1.26 & $0.79-2.02$ \\
\hline \multicolumn{5}{|c|}{ Delivery services utilization (Ref: Poor) } \\
\hline Good & $28.4 *$ & $18.9-42.6$ & $27.4 *$ & $17.3-43.5$ \\
\hline
\end{tabular}

Urban mothers are 1.76 times more likely to have a good utilization of PNC. It is similar with another study that found utilization of PNC in the rural area is lower than in the urban area. Inequity between urban-rural, rich-poor and regions reflects the health care situation in Indonesia. The capital city Jakarta and other big cities in Java-Bali have larger number of health facilities and health workers [16].

Urban area has more facilities and access in services. The number of health workers and access to technological sophistication is also better, thus urban mothers can give birth assisted by health workers and get immediate care afterward. It is different with mothers who live in rural areas where the number of health 
workers is smaller and mostly are still being cared for by traditional birth attendants which are not recommended. Similar with ANC and delivery services utilization, PNC utilization among adolescent mothers who lived in Sumatra, Kalimantan, and eastern Indonesia is lower than those who lived in Java-Bali region. In outside Java-Bali region, the number of health workers is less and the sophistication of telecommunications is lower than Java-Bali, which makes it more difficult to get health workers to perform care at home after childbirth. Difficulty of access and lower quality of maternal health care makes the lack of ANC, delivery services and PNC utilization. This shows that health development in Indonesia is still playing the old song, namely Java-Bali centric and has not been evenly distributed in every region in Indonesia.

The utilization of previous health services which are ANC and delivery services is also a crucial factor in the PNC utilization. Adolescent mothers who have a good utilization of delivery services are more likely to have a good PNC utilization. Giving birth in a health facility will often get PNC services directly. It shows that there is a continuum of care that mothers who use childbirth services may also plan to use the PNC service.

Another study found that non-utilization of postnatal care services was associated to lack of ANC visit, gave births in non-health facilities, and use of untrained birth attendants. Similar with that study, the analysis showed highly significant association between utilization of delivery services and PNC. The study indicated a strong need to improve the access and coverage of all maternal health services and increase community awareness about the importance of delivery services utilization [29].

Other than delivery services, ANC utilization are also having a positive association with utilization of PNC, although from this study's result is not statistically different. Other studies reported that mothers with at least four ANC visits increased the delivery services utilization and had shown a substantial effect on the utilization of PNC [9], [30]. These indicate the need to strengthen continuum of care in maternity care to improve adolescent mother's utilization of maternity health services.

\subsection{Strength and limitation}

As using a national survey data, this study is representative for adolescent mothers in Indonesia. This study assessed the maternal health services utilization in all maternal period, during pregnancy, delivery, and postnatal in vulnerable population, which is adolescent age 15-19 years old. From the results found the association between region and maternal health services that can be used to develop strategic planning and program, especially as health system in Indonesia is decentralization. The Indonesia Demographic Health Survey (IDHS) provided limited information on certain topics and variables that may be less explored in the results. Furthermore, all variables were assumed to be fixed over five years before the survey.

\section{CONCLUSION}

As the study found that region was significantly associated with the three utilizations which are ANC, delivery services, and PNC utilization, it reflects that there are region disparities especially between Java-Bali and outside Java-Bali. Region outside Java-Bali which has lower maternal health services utilization needs to improve their access and quality of care for maternal health services. It can be done by adding the number of health facilities and health providers, providing the training for health providers particularly about ANC, delivery services, and PNC, and giving massive information about maternal health in community as well as in youth-friendly health care.

This study also showed that support from husband in accompanying their wives during pregnancy check gives a big impact in using maternal health services. It means that male involvement in maternal health is essential and needs to encourage more. Education related to maternal health can be provided not only for women but also for men to improve their knowledge and gives more support to their wives/partners during pregnancy, childbirth, and postpartum period. In addition, program to provide education about high-risk pregnancy should be implemented in national level until district/city level to prevent the early age pregnancy and improve the knowledge of mothers about maternal health.

\section{REFERENCES}

[1] WHO, “Maternal mortality,” 2019. https:/www.who.int/news-room/fact-sheets/detail/maternal-mortality. (accessed Jun. 10, 2021).

[2] WHO, “Adolescent pregnancy," 2020. https:/www.who.int/news-room/fact-sheets/detail/adolescent-pregnancy (accessed Oct. 14, 2021).

[3] E. Erfina, W. Widyawati, L. McKenna, S. Reisenhofer, and D. Ismail, "Exploring Indonesian adolescent women's healthcare needs as they transition to motherhood: A qualitative study," Women and Birth, vol. 32, no. 6, pp. e544-e551, Dec. 2019, doi: 10.1016/j.wombi.2019.02.007.

[4] United Nations, "The Millennium Development Goals 2015," https://www.un.org/millenniumgoals/2015_MDG_Report/pdf/MDG 2015 rev (July 1).pdf. (accessed Jun. 11, 2021).

Int J Public Health Sci, Vol. 11, No. 1, March 2022: 77-87 
[5] Bappenas, "Report of the Indonesia Millenium Development Goals 2014 (In Indonesia: Laporan Tujuan Pembangunan Milenium Indonesia 2014)." Bappenas Jakarta, Indonesia, 2015. https://www.scribd.com/doc/294394332/Laporan-MDGs-2014-Final (accessed Jun. 10, 2021).

[6] Statistics Indonesia, National Population and Family Planning Board, Ministry of Health, MEASURE DHS, and ICF International, "Indonesia Demographic and Health Survey 2012," 2013. https://dhsprogram.com/pubs/pdf/fr275/fr275.pdf (accessed Oct. 14, 2021).

[7] A. Kurniati, C.-M. Chen, F. Efendi, and S. M. Berliana, "Factors influencing Indonesian women's use of maternal health care services," Health Care for Women International, vol. 39, no. 1, pp. 3-18, Jan. 2018, doi: 10.1080/07399332.2017.1393077.

[8] Z. Çalışkan, D. Kılıç, S. Öztürk, and E. Atılgan, "Equity in maternal health care service utilization: a systematic review for developing countries," International Journal of Public Health, vol. 60, no. 7, pp. 815-825, Nov. 2015, doi: 10.1007/s00038-0150711-X.

[9] R. K. Rai, P. K. Singh, C. Kumar, and L. Singh, "Factors associated with the utilization of maternal health care services among adolescent women in Malawi," Home Health Care Services Quarterly, vol. 32, no. 2, pp. 106-125, Apr. 2013, doi: 10.1080/01621424.2013.779354.

[10] A. E. Rahman et al., "Knowledge and involvement of husbands in maternal and newborn health in rural Bangladesh," BMC Pregnancy and Childbirth, vol. 18, no. 1, p. 247, Dec. 2018, doi: 10.1186/s12884-018-1882-2.

[11] A. Probandari, A. Arcita, K. Kothijah, and E. P. Pamungkasari, "Barriers to utilization of postnatal care at village level in Klaten district, central Java Province, Indonesia,” BMC Health Services Research, vol. 17, no. 1, p. 541, Dec. 2017, doi: 10.1186/s12913017-2490-y.

[12] J. K. Kabakyenga, P.-O. Östergren, E. Turyakira, and K. O. Pettersson, "Knowledge of obstetric danger signs and birth preparedness practices among women in rural Uganda," Reproductive Health, vol. 8, no. 1, p. 33, Dec. 2011, doi: 10.1186/17424755-8-33.

[13] L. Chen et al., "Coverage, quality of and barriers to postnatal care in rural Hebei, China: a mixed method study," BMC Pregnancy and Childbirth, vol. 14, no. 1, p. 31, Dec. 2014, doi: 10.1186/1471-2393-14-31.

[14] V. Sychareun et al., "Determinants of adolescent pregnancy and access to reproductive and sexual health services for married and unmarried adolescents in rural Lao PDR: a qualitative study," BMC Pregnancy and Childbirth, vol. 18, no. 1, p. 219, Dec. 2018, doi: 10.1186/s12884-018-1859-1.

[15] C. S. Acuin et al., "Maternal, neonatal, and child health in southeast Asia: towards greater regional collaboration," Lancet (London, England), vol. 377, no. 9764, pp. 516-525, Feb. 2011, doi: 10.1016/S0140-6736(10)62049-1.

[16] H. Y. Nababan, M. Hasan, T. Marthias, R. Dhital, A. Rahman, and I. Anwar, "Trends and inequities in use of maternal health care services in Indonesia, 1986-2012," International Journal of Women's Health, vol. 10, pp. 11-24, Dec. 2017, doi: 10.2147/IJWH.S144828

[17] M. C. Chikalipo, E. M. Chirwa, and A. S. Muula, "Exploring antenatal education content for couples in Blantyre, Malawi," BMC Pregnancy and Childbirth, vol. 18, no. 1, p. 497, Dec. 2018, doi: 10.1186/s12884-018-2137-y.

[18] T. Mekonnen, T. Dune, and J. Perz, "Maternal health service utilisation of adolescent women in sub-Saharan Africa: a systematic scoping review," BMC Pregnancy and Childbirth, vol. 19, no. 1, p. 366, Dec. 2019, doi: 10.1186/s12884-019-2501-6.

[19] A. S. M. Shahabuddin, T. Delvaux, S. Abouchadi, M. Sarker, and V. De Brouwere, "Utilization of maternal health services among adolescent women in Bangladesh: A scoping review of the literature," Tropical Medicine \& International Health, vol. 20, no. 7, pp. 822-829, Jul. 2015, doi: 10.1111/tmi.12503.

[20] E. B. Turinawe et. al., "Traditional birth attendants (TBAs) as potential agents in promoting male involvement in maternity preparednedd: insights from a rural community in Uganda," Reproductive Health, vol. 13, no. 24, pp. 1-11, Mar. 2016, doi: 10.1186/s12978-016-0147-7.

[21] B. K. Sarker, M. Rahman, T. Rahman, J. Hossain, L. Reichenbach, and D. K. Mitra, "Reasons for Preference of Home Delivery with Traditional Birth Attendants (TBAs) in Rural Bangladesh: A Qualitative Exploration," PLOS ONE, vol. 11, no. 1, p. e0146161, Jan. 2016, doi: 10.1371/journal.pone.0146161.

[22] J. Svanemyr, V. Chandra-Mouli, C. S. Christiansen, and M. Mbizvo, "Preventing child marriages: first international day of the girl child "my life, my right, end child marriage," Reproductive Health, vol. 9, no. 1, pp. 31-33, Dec. 2012, doi: 10.1186/17424755-9-31.

[23] L. Cameron, D. Contreras Suarez, and K. Cornwell, "Understanding the determinants of maternal mortality: An observational study using the Indonesian population census," PLOS ONE, vol. 14, no. 6, pp. 1-18, Jun. 2019, doi: 10.1371/journal.pone.0217386.

[24] P. K. Singh, R. K. Rai, M. Alagajaran, L. Singh, "Determinants of maternity care services utilization among married adolescents in Rural India," PLOS ONE, vol. 7, no. 2, pp. 1-14, Feb. 2012, doi: 10.1371/journal.pone.0031666.

[25] J. P. Azavedo, M. Favara, S. E. Haddock, L. F. Lopez-Calva, M. Muller, E. Perova, "Teenage pregnancy and opportunities in Latin America and the Caribbean on teenage fertility decisions, poverty and economic achievement," 2012. https://openknowledge.worldbank.org/bitstream/handle/10986/16978/831670v20REVIS00Box385190B00PUBLIC0.pdf?sequenc $\mathrm{e}=5$ (accessed Nov. 10, 2021).

[26] S. Mbugua and K. L. D. Macquarrie, "Determinants of maternal care seeking in Kenya," 2018. https://dhsprogram.com/pubs/pdf/AB3/FA111.pdf. (accessed Jun. 10, 2021).

[27] R. K. Rai, P. K. Singh, and L. Singh, "Utilization of maternal health care services among married adolescent women: Insights from the Nigeria demographic and health survey, 2008," Women's Health Issues, vol. 22, no. 4, pp. e407-e414, Jul. 2012, doi: 10.1016/j.whi.2012.05.001.

[28] G. A. Fekadu, G. M. Kassa, A. K. Berhe, A. A. Muche, and N. A. Katiso, "The effect of antenatal care on use of institutional delivery service and postnatal care in Ethiopia: a systematic review and meta-analysis," BMC Health services Research, vol. 18, no. 577, Jul. 2018, doi: 10.1186/s12913-018-3370-9.

[29] C. R. Titaley, M. J. Dibley, and C. L. Roberts, "Factors associated with non-utilisation of postnatal care services in Indonesia," Journal of Epidemiology \& Community Health, vol. 63, no. 10, pp. 827-831, Oct. 2009, doi: 10.1136/jech.2008.081604.

[30] H. Birungi, F. Obare, A. van der Kwaak, and J. H. Namwebya, "Maternal health care utilization among HIV-positive female adolescents in Kenya," International Perspectives on Sexual and Reproductive Health, vol. 37, no. 03, pp. 143-149, Sep. 2011, doi: $10.1363 / 3714311$. 